\title{
KARAKTERISTIK IBU BERDASARKAN PENGGUNAAN ALAT PERMAINAN EDUKATIF (APE) UNTUK MENSTIMULASI ANAK PRA SEKOLAH
}

\section{CHARACTERISTICS OF MOTHER BASED ON THE USE OF EDUCATIVE GAME TO STIMULATE CHILDREN PRE-SCHOOL}

\author{
Erien Luthfia ${ }^{1}$, Hadi Kusuma Atmaja ${ }^{2}$ \\ ${ }^{1}$ Jurusan Kebidanan, Poltekkes Kemenkes Mataram \\ ${ }^{2}$ Jurusan Keperawatan, Poltekkes Kemenkes Mataram \\ Korespondensi:erien.luthfia@gmail.com
}

\begin{abstract}
The preschool period is the beginning of the development of physical abilities, cognitive, language, social-emotional, self-concept, discipline, independence, art, morals, and religious values. Therefore, so that the child's growth and development can be optimally needed and stimulation that suits the child's needs, can be done by the mother. A preliminary study conducted in the Sandik, Batu Layar, Lombok Barat, NTB about the use of educational play instruments by interviewing 10 mothers, the results obtained, 7 mothers provided educational play tools for users by using tools and benefits of play tools. APE to stimulate preschool children in 2019. The research design is descriptive method. The population in this study is mothers who have preschool children. The sampling technique is saturated sampling with a large sample of 45 people. Data collection using questionnaires. The results showed that most respondents were aged 20-35 years (71.1\%), had secondary education (SMP / SMA / equivalent) as much as $64.4 \%$, and as many as $66.7 \%$ of respondents were working mothers. The knowledge of respondents in the good category was $64.4 \%$. This study concludes that the characteristics of respondents who use APE to stimulate pre-school children are aged 20-35 years, have secondary education, work, and have a good level of knowledge. For this reason, mothers should continue to improve their knowledge of educational game tools through the correct sources of information.
\end{abstract}

Keywords: Characteristics of mothers, Educational Game Tools, Stimulation, PreSchool Children

\begin{abstract}
ABSTRAK
Masa pra sekolah merupakan masa awal pengembangan kemampuan fisik, kognitif, bahasa, sosial emosional, konsep diri, disiplin, kemandirian, seni, moral, dan nilai-nilai agama. Oleh karena itu, agar pertumbuhan dan perkembangan anak dapat tercapai secara optimal dibutuhkan kondisi dan stimulasi yang sesuai dengan kebutuhan anak, terutama bisa dilakukan oleh ibu. Studi pendahuluan yang dilakukan di Desa Sandik Batu Layar Lombok Barat tentang penggunaan alat permainan edukatif dengan
\end{abstract}


mewawancarai $10 \mathrm{ibu}$, hasil yang di dapatkan, $7 \mathrm{ibu}$ memberikan alat permainan edukatif kepada anaknya dengan memperhatikan fungsi dan manfaat alat permainan. Penelitian ini bertujuan untuk mengetahui karakteristik ibu yang menggunakan APE untuk menstimulai anak pra sekolah Tahun 2019. Desain penelitian yaitu metode deskriptif. Populasi dalam penelitian ini adalah Ibu yang memiliki anak pra sekolah. Teknik pengambilan sampel yaitu sampling jenuh dengan besar sampel 45 orang. Pengumpulan data menggunakan kuisioner. Hasil penelitian menunjukkan bahwa responden paling banyak berada pada usia 20-35 tahun (71.1\%), berpendidikan menengah (SMP/SMA/sederajat) sebanyak 64.4\%, dan sebanyak $66.7 \%$ responden adalah ibu bekerja. Pengetahuan responden pada kategori baik sebanyak $64.4 \%$. Kesimpulan penelitian ini adalah karakteristik responden yang menggunakan APE untuk menstimulasi anak pra sekolah adalah usia 20-35 tahun, berpendidikan menengah, bekerja, dan tingkat pengetahuannya baik. Untuk itu disarankan kepada Ibu agar terus meningkatkan pengetahuan tentang alat permainan edukatif melalui berbagai sumber informasi yang benar.

\section{Kata kunci: Karakteristik ibu, Alat Permainan Edukatif, Stimulasi, Anak Pra Sekolah}

\section{PENDAHULUAN}

Anak usia pra sekolah merupakan anak yang memasuki masa yang peka, karena masa ini merupakan masa terjadinya pematangan fungsi-fungsi fisik dan psikis yang siap merespons stimulasi lingkungan dan menginternalisasikanke dalam pribadinya. Masa ini merupakan masa awal pengembangan kemapuan fisik, kognitif, bahasa, sosial emosional, konsep diri, disiplin, kemandirian, seni, moral, dan nilai-nilai agama Oleh karena itu, agar pertumbuhan dan perkembangan anak dapat tercapai secara optimal dibutuhkan kondisi dan stimulasi yang sesuai dengan kebutuhan anak (Mutiah, 2012).
Salah satu stimulusi bagi perkembangan anak secara optimal adalah dengan bermain. Sekarang ini banyak sekali dijual macam-macam alat permainan. Apabila orang tua tidak selektif dan kurang memahami fungsinya, alat permainan yang dibelinya tidak dapat berfungsi secara efektif (Rekawati, dkk, 2013).

Banyak orang tua membeli alat permainan yang mereka pikir indah dan menarik, tetapi mereka tidak berfikir apa yang dikerjakan anak terhadap alat permainan itu dan manfaat yang diperoleh anak dari alat permainan tersebut. Selain itu banyak pula orang tua yang berpendapat bila mainan itu 
mahal maka mempunyai nilai mendidik sekaligus menghibur. Hal ini menunjukkan bahwa pengetahuan orang tua masih kurang tentang alat permainan edukatif (Soetjiningsih, 2012).

Kenyataannya saat ini permainan yang menyebar di masyarakat lebih banyak didominasi permainan nonedukatif sehingga tidak sedikit mainan yang diproduksi dari pabrik memiliki fungsi yang kurang dalam menunjang tumbuh kembang anak. Alat permainan tersebut antara lain kartu bergambar, manusia karet, video games, mainan elektronik dan mainan berbasis komputer lainnya. Salah satu contoh permainan elektronik seperti permainan berupa pertarungan atau pertandingan tinju, dengan gambar animasi pahlawan, hanya akan menanamkan sifat-sifat kekerasan sebab anak akan meniru apa yang dilihat (Suyadi, 2009).

Alat permainan edukatif (APE) merupakan alat permainan yang fungsinya dapat mengoptimalkan perkembangan (aspekfisik, bahasa, kognitif, dansosial) anak, hal ini tentPolpunya disesuaikan dengan tingkat usia dan perkembangannya (Riyadi dan Sukarmin, 2009). Alat permainan edukatif ini memegang peranan penting dalam kehidupan anak, terutama pada masa prasekolah.

Berdasarkan studi pendahuluan yang dilakukan peneliti pada tanggal 4 februari 2019 di PAUD Almuwahidin Desa Lelede Kecamatan Kediri Kabupaten Lombok Barat tentang alat permainan edukatif dengan cara mewawancarai 3 ibu yang mempunyai anak yang berumur 3-6 Tahun di PAUD Almuwahidin Desa Lelede Kecamatan Kediri Kabupaten Lombok Barat. Didapatkan hasil bahwa, ketiga ibu hanya memberikan alat permainan kepada anaknya dengan seadanya atau semampu ibunya saja. Mereka memberikan alat permainan hanya untuk kesenangan anaknya tanpa memperhatikan fungsi dan manfaat dari alat permainan tersebut bagi perkembangan anaknya. Mengingat orang tua memiliki tanggung jawab untuk mendidik, mengasuh dan membimbing anak-anaknya maka perlu dilakukan pemantauan dan sosialisasi terhadap permainan edukatif agar pengetahuan orang tua tentang alat permainan edukatif pada anak-anaknya agar dapat berkembang secara optimal. Dari uraian di atas, maka peneliti tertarik untuk meneliti tentang pengetahuan ibu tentang alat permainan 
edukatif pada anak 3-6 tahun PAUD Almuwahidin Desa Lelede Kecamatan Kediri Kabupaten Lombok Barat Tahun 2019.

\section{METODE}

Penelitian ini merupakan jenis penelitian deskriptif (Non Eksperimen). Metode pengumpulan data yang digunakan adalah metode survey dengan menggunakan kuesioner sebagai alat pengumpul data. Data yang digunakan adalah data primer dan data skunder. Penelitian ini dilakukan pada bulan November sampai dengan Desember 2019 di Desa Sandi Kecamatan Batu Layar Kabupaten Lombok Barat.

Populasi dalam penelitian ini adalah ibu yang mempunyai anak pra sekolah, dengan teknik pengambilan sampel adalah sampel jenuh. Sampel dalam penelitian ini sebanyak 45 ibu. Pengumpulan data menggunakan data primer dan data skunder.

HASIL DAN PEMBAHASAN

Karakteristik

Responden

berdasarkan umur
Responden menurut umur yang memiliki anak usia pra sekolah di dapat dilihat pada tabel berikut.

Tabel 1. Distribusi Umur Responden

\begin{tabular}{ccc}
\hline $\begin{array}{c}\text { Umur } \\
\text { (Tahun) }\end{array}$ & $\mathbf{f}$ & $\mathbf{( \% )}$ \\
\hline$<20$ & 1 & 2.2 \\
\hline $20-35$ & 32 & 71.1 \\
\hline$>35$ & 12 & 26.7 \\
\hline Total & $\mathbf{4 5}$ & $\mathbf{1 0 0}$ \\
\hline
\end{tabular}

Menurut tabel 1 diatas, didapatkan hasil bahwa sebagian besar responden berada pada kategori usia 20-35 tahun sebanyak 32 orang $(71.1 \%)$.

\section{Karakteristik Responden}

Berdasarkan Tingkat Pendidikan

Tabel 2. Distribusi Responden Berdasarkan Tingkat Pendidikan

\begin{tabular}{lcc}
\hline \multicolumn{1}{c}{$\begin{array}{c}\text { Tingkat } \\
\text { Pendidik } \\
\text { an }\end{array}$} & f & \% \\
\hline Dasar & 6 & 13.3 \\
\hline Menengah & 29 & 64.4 \\
\hline Tinggi & 8 & 17.8 \\
\hline Tidak & 2 & 4.4 \\
Sekolah & & \\
\hline Total & 45 & 100 \\
\hline
\end{tabular}

Berdasarkan tabel diatas didapatkan hasil bahwa sebagian besar responden terdapat pada kategori tingkat pendidikan menengah yaitu sebanyak 29 orang $(64.4 \%)$. 
Karakteristik

Berdasarkan Pekerjaan

Tabel 3. Distribusi Responden

Berdasarkan Pekerjaan

\begin{tabular}{lcc}
\hline Pekerjaan & f & \% \\
\hline Bekerja & 30 & 66,7 \\
\hline $\begin{array}{c}\text { Tidak } \\
\text { Bekerja }\end{array}$ & 15 & 33,3 \\
\hline Total & 45 & 100 \\
\hline
\end{tabular}

Berdasarkan diatas menunjukkan bahwa sebagian besar Ibu bekerja yaitu sebanyak 30 orang $(66,7 \%)$.

\section{Karakteristik}

Responden

\section{Berdasarkan Pengetahuan}

Pada penelitian ini, data dan hasil mengenai pengetahuan responden tentang Alat Permainan Edukatif untuk anak Pra Sekolah diperoleh melalui kuesioner yang memuat 20 pernyataan mengenai alat permainan edukatif. Pengetahuan responden tentang Alat Permainan Edukatif Pada anak 3-6 tahun dapat dilihat pada tabel berikut.

Tabel 4. Distribusi Pengetahuan ang Alat Permainan Edukatif.

\begin{tabular}{ccc}
\hline $\begin{array}{c}\text { Tingkat } \\
\text { Pengatahuan } \\
\text { Responden }\end{array}$ & F & \% \\
\hline Baik & 29 & 64.4 \\
\hline Cukup & 13 & 28.9 \\
\hline Kurang & 3 & 6,7 \\
\hline Total & 45 & 100 \\
\hline
\end{tabular}

Berdasarkan tabel diatas menunjukkan bahwa pengetahuan responden tentang Alat Permainan Edukatif untuk menstimulasi anak pra sekolah sebagian besar dengan kategori pengetahuan baik yaitu sebanyak 29 orang (64.4\%).

\section{Karakteristik Berdasarkan Umur}

Umur adalah lamanya hidup seseorang dalam tahun yang dihitung sejak dilahirkan hingga saat ini. Menurut teori Hurlock (1998) dalam Wawan dan Dewi (2010), semakin baik umur tingkat kematangan dan kekuatan seseorang akan lebih matang dalam berpikir. Semakin bertambahnya umur seseorang maka pengetahuan dan pengalaman seseorang akan semakin baik. Berdasarkan hasil penelitian didapatkan karakteristik Responden menurut umur sebagian besar berada pada rentang umur 20-35 tahun yaitu sebanyak $71.1 \%$. Hal ini menunjukkan bahwa hasil penelitian yang didapatkan sesuai dengan teori yang dikemukakan karena usia 20-35 merupakan usia produktif yang kemungkinan dapat mendukung kemampuan Responden dalam belajar dan mengingat informasi yang diperoleh.

Usia 20-35 ini merupakan usia produktif yang dapat mendukung 
kemampuan responden dalam belajar dan mengingat informasi yang diperoleh. Sesuai dengan pendapat Cropton, J (1997) yang menyatakan bahwa usia produktif merupakan usia dewasa yang aktif dalam kegiatan sehingga mendukung dalam belajar dan mengingat informasi yang diperoleh. Kemampuan yang baik cenderung dimiliki pada umur muda.Seseorang pada umur muda cenderung memiliki daya ingat lebih kuat dan kreativitas lebih tinggi dalam mencari dan mengenal sesuatu yang belum diketahui (Depkes, 1997).

Abu Ahmadi (2001) menyatakan bahwa memang daya ingat seseorang itu salah satunya dipengaruhi oleh umur. Selain itu Singgih (1989) juga mengemukakan bahwa makin tua umur seseorang maka proses-proses perkembangan mentalnya bertambah baik, akan tetapi pada umur tertentu, bertambahnya proses perkembangan mental ini tidak secepat seperti ketika berumur belasan tahun.

Berdasarkan uraian ini maka dapat disimpulkan bahwa bertambahnya umur seseorang dapat berpengaruh pada pertambahan pengetahuan yang diperolehnya, akan tetapi pada umurumur tertentu atau menjelang usia lanjut kemampuan penerimaan atau mengingat suatu pengetahuan akan berkurang.

Berdasarkan pernyataan para ahli dan hasil penelitian yang didapat secara umum kedua data tersebut sesuai yaitu usia Responden yang berada pada usia produktif (20-35 tahun) merupakan usia dewasa yang aktif dalam kegiatan sehingga mendukung dalam belajar dan mengingat informasi yang diperoleh, dan dilihat dari hasil penelitian umur Responden terbanyak yang berada pada usia 20-35 sebagian besarmemiliki pengetahuan baik.

\section{Karakteristik Berdasarkan Pendidikan}

Pada hasil penelitian, Responden terbanyak berada pada tingkat pendidikan menengah yaitu sebanyak 64.4\%, dimana dengan pendidikan menengah ini bisa dikatakan bahwa responden mampu untuk menerima informasi dibandingkan dengan Responden yang pendidikannya lebih rendah karena pada tingkat pendidikan menengah itu berada disaat kondisi pemikiran yang cukup stabil.

Hal ini sesuai dengan pendapat Harry, A (1996) dalam Notoatmodjo (2003) yang menyatakan bahwa tingkat pendidikan turut pula menentukan mudah tidaknya seseorang menyerap 
dan memahami pengetahuan yang mereka peroleh. Ini berarti tingkat pendidikan Responden akan mempengaruhi tingkat pengetahuan Responden dan secara langsung akan mempengaruhi tingkat perkembangan anak.

Pendidikan Responden dapat menunjukkan kualitas pengetahuan yang dimiliki. Dalam memahami sesuatu informasi atau masalah yang dihadapi, dapat mempengaruhi setiap Responden dalam merawat dan mengambil keputusan yang berhubungan dengan alat permainan eduaktif pada anak yang sesuai dengan usia dan tahap perkembanganya.

Berdasarkan pernyataan para ahli dan hasil penelitian yang didapat secara umum, kedua data tersebut sesuai yaitu Responden dengan pendidikan menengah pengetahuannya cukup baik di bandingkan dengan Responden yang pendidikannya lebih rendah atau hanya sampai pendidikan dasar.Sehingga dapat disimpulkan bahwa semakin tinggi tingkat pendidikan seseorang maka semakin baik pula kemampuannya dalam memahami ilmu dan informasi tertentu.

\section{Karakteristik}

Responden

\section{Berdasarkan Pekerjaan}

Selain itu juga, faktor yang dapat mempengaruhi pengetahuan Responden dapat dipengaruhi oleh bekerja atau tidaknya Responden tersebut dari segi pekerjaannya. Dalam penelitian ini paling banyak adalah Responden yang bekerja sebanyak 30 orang $66,7 \%$. Pengetahuan Responden yang bekerja lebih baik bila dibandingkan dengan pengetahuan Responden yang tidak bekerja. Semua ini disebabkan karena Responden yang bekerja di luar rumah (sektor formal) memiliki akses yang lebih baik terhadap berbagai informasi khususnya mengenai alat permainan edukatif pada Anak 3-6 tahun baik yang diperoleh melalui sumber media cetak (majalah, jurnal kesehatan) maupun sumber media elektronik (TV, internet) menjadikan Responden tidak mengalami kesulitan di dalam menjawab pernyataan yang diajukan.

Ditinjau dari segi pekerjaan Responden yang bekerja sebagai PNS, swasta, wiraswasta, TNI, pedagang, buruh dan petani sebanyak $66,7 \%$ dan tidak bekerja yaitu hanya sebagai Responden rumah tangga sebanyak 33,3\%. Dimana Responden yang bekerja sebanyak $66,7 \%$ ini sebagian besar terdapat pada kategori berpengetahuan baik yaitu sebanyak 
56,7\%, lalu pada kategori pengetahuannya cukup sebanyak $36,6 \%$, serta $6,7 \%$ terdapat pada kategori pengetahuan kurang.

Hal ini sesuai dengan pendapat Depkes RI (1999), yang menyatakan pengetahuan Responden yang bekerja lebih baik bila dibandingkan dengan pengetahuan Responden yang tidak bekerja.Semua ini disebabkan karena Responden yang bekerja di luar rumah (sektor formal) memiliki akses yang lebih baik terhadap berbagai informasi.

Informasi dan pengalaman dapat diperoleh ketika seseorang melakukan interaksi dengan orang lain saat seseorang bekerja ataupun saat seseorang melakukan hubungan sosial. Dengan melakukan interaksi atau hubungan sosial memungkinkan Responden mendapatkan informasi dan pengalaman termasuk tentang Permainan Edukatif pada Anak 3-6 tahun, hal ini akan menambah pengetahuan Responden khususnya tentang Permainan Edukatif pada Anak 3-6 tahun.

(2003) yang menyatakan seseorang yang mempunyai informasi yang lebih banyak akan memiliki pengetahuan yang luas. Informasi tersebut bisa diperoleh dari berbagai sumber seperti media cetak (surat kabar, majalah, jurnal kesehatan, dan lain-lain) dan media elektronik (TV, internet) serta dengan adanya pengalaman atau kontak dengan lingkungan fisik.

\section{Pengetahuan Responden tentang Alat Permainan Edukatif}

Berdasarkan hasil penelitian yang didapatkan dari 45 Responden menunjukkan bahwa sebagian besar Responden memiliki pengetahuan yang baik yaitu sebanyak $64.4 \%$ adapun sebanyak 6,7\% Responden yang masih memiliki pengetahuan kurang. Responden yang kategori pengetahuannya baik mengetahui tentang pengertian, syarat-syarat, dan prinsip dasar dari alat permainan edukatif namun kurang mengetahui tentang kesalahan-kesalahan dalam memilih alat permainan edukatif, contoh alat permainan untuk perkembangan anak, alat permainan yang dianjurkan untuk anak usia pra sekolah dan tujuannya. Kategori pengetahuan baik ini dapat dikatakan bahwa Responden sudah sepenuhnya mampu menjawab dengan benar dari 20 pernyataan yang diajukan mengenai alat permainan edukatif. Notoatmodjo (2005) mengatakan bahwa pengetahuan 
seseorang tidak lepas dari faktor yang mempengaruhinya yaitu: umur, pendidikan dan pekerjaan.

Pengetahuan adalah hasil tahu dan ini terjadi setelah orang melakukan pengindraan terhadap objek tertentu, yakni: indra penglihatan,pendengaran, penciuman, rasa, dan raba . sebagian besar pengetahuan diperoleh melalui mata dan telinga. Notoatmodjo (2010) Bahwa pengetahuan seseorang dipengerahui banyak faktor, seperti pendidikan umur, pekerjaan, dan faktor eksternal lainya.

\section{SIMPULAN}

Karakteristik responden berdasarkan umur sebagian besar berusia 20-35 tahun, pendidikan paling banyak adalah pada tingkat pendidikan menengah (SMP,SMA/sederajat), kemudian dari segi pekerjaan sebagian besar responden bekerja. Pengetahuan responden tentang Permainan Edukatif paling banyak memiliki pengetahuan baik. Diharapkan responden lebih meningkatkan pengetahuannya tentang Permainan Edukatif melalui berbagai sumber informasi yang benar seperti majalah, buku, internet, maupun TV. Tenaga kesehatan terutama bidan dan perawat diharapkan memberikan penyuluhan atau informasi kepada responden tentang alat permainan yang edukatif.

\section{DAFTAR PUSTAKA}

Ahmadi, Abu. 2001. Ilmu Pendidikan. PT. RinekaCipta: Jakarta

Brooks, J. 2011. The Process of Parenting.PustakaPelajar:

Yogyakarta

Depkes RI. 1997. Asuhan Kesehatan Anak Dalam Konteks Keluarga. Balai Pustaka: Jakarta

Hidayat, A. A. 2012.Pengantar Ilmu Keperawatan Anak 1. Jakarta: Salemba Medika

Marmidan Rahardjo, K. 2012.Asuhan Neonatus, Bayi, Balita, dan Anak Prasekolah. Yogyakarta: Pustaka Pelajar

Mutiah, D. 2012. Psikologi Bermain Anak Usia Dini. Kencana: Jakarta

Nirwana, A. 2011.Psikologi Bayi, Balita, dan Anak. Nuha Medika: Yogyakarta

Rekawati, Nursalam, dan Utami. 2013 .Asuhan Keperawatan Bayi dan Anak: Untuk Perawat dan Bidan Edisi 2.Salemba Medika: Jakarta

Riadi, Sujona dan Sukarmin.2009. Asuhan Keperawatan pada Anak. Graha Ilmu: Jakarta

Santrock, J. W. 2007. Perkembangan Anak Edisi Kesebela sJilid 2. Erlanga: Jakarta 
Soetjiningsih . 2012. Tumbuh Kembang Anak. EGC: Jakarta

Suherman. 2000. Buku Saku Perkembangan Anak. EGC: Jakarta

Suyadi. 2009. Permainan Edukatif yang Mencerdaskan. Power Books: Jakarta

Wawan dan Dewi M. 2010. Teori dan Pengukuran Pengetahuan, Sikap, dan Perilaku Manusia. Nuha Medika: Yogyakarta 